Article

\title{
Evaluation of Environmental Influences on a Multi-Point Optical Fiber Methane Leak Monitoring System
}

\author{
Claudio Floridia ${ }^{1, *(\mathbb{D})}$, Joao Batista Rosolem ${ }^{1}{ }^{1}$, João Paulo Vicentini Fracarolli ${ }^{1}$, \\ Fábio Renato Bassan ${ }^{1}$, Rivael Strobel Penze ${ }^{1}$ (D), Larissa Maria Pereira ${ }^{2}$ \\ and Maria Angélica Carmona da Motta Resende ${ }^{2}$ \\ 1 CPqD Research and Development Center, Campinas - SP 13086-902, Brazil; rosolem@cpqd.com.br (J.B.R.); \\ jpaulo@cpqd.com.br (J.P.V.F.); fbassan@cpqd.com.br (F.R.B.); rpenze@cpqd.com.br (R.S.P.) \\ 2 CENPES Petrobras Research and Development Center, Rio de Janeiro - RJ 21941-915, Brazil; \\ larissapereira@petrobras.com.br (L.M.P.); angelicamotta@petrobras.com.br (M.A.C.d.M.R.) \\ * Correspondence: floridia@cpqd.com.br
}

Received: 7 May 2019; Accepted: 9 May 2019; Published: 27 May 2019

check for updates

\begin{abstract}
A novel system to monitor methane fugitive emissions was developed using passive optical sensors to attend to the natural gas production and transportation industry. The system is based on optical time domain reflectometry and direct optical absorption spectroscopy. The system was tested in a gas compressor station for four months. The system was capable to measure methane concentration at two points showing its correlation with meteorological data, specially wind velocity and local temperature. Methane concentrations varied from $2.5 \%$ to $15 \%$ in the first monitored point by sensor 1 , and from $5 \%$ to $30 \%$, in the second point with sensor 2 . Both sensors exhibited a moderate negative correlation with wind velocity with a mean Pearson coefficient of -0.61 , despite the external cap designed to avoid the influence of wind. Sensor 2 had a modification to its external package that reduced this mean correlation coefficient to -0.30 , considered to be weak to negligible. Regarding temperature, a moderate mean correlation of -0.59 was verified for sensor 1 and zero mean correlation was found for sensor 2 . Based on these results the system was proven to be robust for installation in gas transportation or processing facilities.
\end{abstract}

Keywords: methane; leak; optical fiber; optical sensors; optical absorption; OTDR

\section{Introduction}

Optical fiber sensor technology has been used for many applications in the oil and gas industry [1]. Due to its linear structure, optical fiber is very interesting to monitor pipelines that provide the transportation of crude and refined petroleum, fuels, natural gas and biofuels. In addition, optical fibers sensors are passive and do not require a power supply, thus making them suitable to use in oil and gas infrastructures.

In natural gas production and the transportation industry, fugitive emissions represent a permanent concern. Emissions, mainly composed of methane, can contribute to the intensification of climate change, since the global warming potential of this gas is 21 times greater than carbon dioxide. Methane emissions also represent a reduction in plant energy efficiency and a risk of explosions that can lead to catastrophic events.

In addition, recent studies [2] have suggested that the tropical regions hold some unexpectedly high methane concentration and that the recent changes in the global methane burden are poorly understood. To address this research gap, efforts must be made to quantify methane emissions from oil and gas infrastructures in tropical regions. 
Thus, the management of atmospheric emissions and the improvement of the operational safety of gas transport infrastructures constitute an important area of research and development.

Many optical fiber techniques have been reported to detect gases, including the development of micro and nano-engineered optical fibers, such as hollow-core fibers, suspended-core fibers, and tapered optical micro/nano fibers [3,4].

Among the possible technologies to be employed in optical gas detection systems, the use of long period grating (LPG) coated with special material have been proposed and tested. In [5], an LPG coated with atactic polystyrene was developed and tested in a railway environment to enable the detection of liquefied petroleum gas, specifically butane gas-the main component of liquefied petroleum gas. In [6], a long-period fiber grating is proposed as a methane sensor by the deposition of high refractive index polycarbonate/cryptophane A overlay. The sensor presented a sensitivity of $\sim 2.5 \mathrm{~nm} . \%^{-1}$ and detection limit of $0.2 \%$. Although the measurement of gas absorption with LPG technology depends on the interaction of a specific coating, and not from the direct optical interaction itself, this technology is interesting as it enables multiplexing and the use of different coatings that could permit the detection of many substances.

Other studies were carried out regarding the multiplexing capability of the gas sensor systems. In $[7,8]$, the authors reported multiplexed multi-point gas detection where hundreds of sensors can be accessed using spatial or time division multiplexing techniques. This technique requires the use of optical delay lines and optical couplers, increasing the complexity of the optical network. One particular proposed system to monitor methane leakage with optical fiber technology is commercially available to industry [9]; however, this solution requires a pair of optical fibers at each monitoring point, which limits the number of sensors that can be deployed.

In this paper, a novel system to monitor and to detect methane fugitive emissions in gas facilities is presented. The operation principle is based in two techniques: optical time domain reflectometry (OTDR) and direct optical absorption spectroscopy. The first technique allows localization in terms of the distance of the sensor. The second technique enables the quantification and identification of the substance by varying the wavelength of the laser within the absorption band of the methane (around $1645.5 \mathrm{~nm}$ ). The proposed system differs from other reported systems because it enables the remote detection and identification of fugitive emission of methane in multiple points by means of only one optical fiber and OTDR technique, which is subjected to an innovative optical frequency scanning process in the absorption region of the analyzed gas. Thus, multiple passive remote sensors can be analyzed using single interrogator equipment with a range of tens of kilometers. The capabilities of methane emission localization and spectral analysis in multiple sensors by a single remote interrogator equipment provides improvements on the control of methane fugitive emissions, increasing the energy efficiency and reducing the environmental impacts, and on the operational safety, avoiding the risk of explosions and catastrophic events.

The system was previously demonstrated in a laboratory [10] and in a real plant field-test [11,12]. In this paper, we present new results of the system in a real plant field-test with focus in the influence of environmental conditions. The results show good performance under the influence of environmental conditions such as wind and temperature. However, even if sensors were designed to reduce the impact of wind, for example, a residual effect on the environmental is still present. In this way, a correlation analysis between the concentration levels with the meteorological parameters is presented.

\section{Proposed System}

The proposed system is based in the optical time domain reflectometry technique and in direct optical absorption spectroscopy technology [10]. The first technique allows localization in terms of the distance of multiple sensors deployed along an optical fiber and the attenuation caused by the gas absorption. The second technology is used to quantify and identify the substance by varying the wavelength of the laser within the absorption band of the methane. The most commonly used bands for methane detection are $\sim 3300 \mathrm{~nm}, \sim 2200 \mathrm{~nm}, \sim 1650 \mathrm{~nm}$, and $\sim 1300 \mathrm{~nm}$. The relative intensities of 
some of these absorption bands are illustrated in Figure 1, obtained through HITRAN database [13], that allows access to spectral data for several substances.

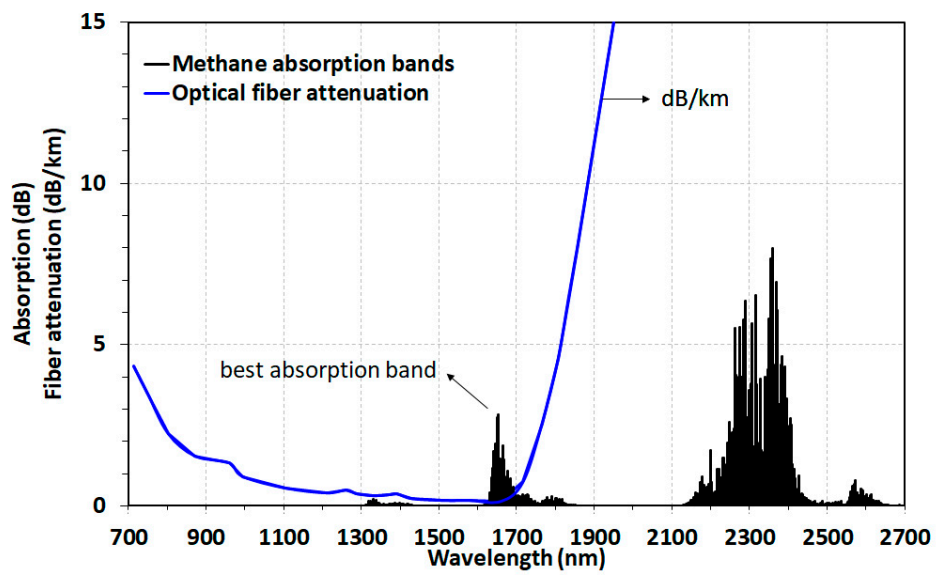

Figure 1. Methane absorption bands (hypothetical $5 \mathrm{~cm}$ cell with pure methane at 50 torr) compared with optical fiber attenuation expressed in $\mathrm{dB} / \mathrm{km}$. Best absorption band for fiber optical application indicated.

The more intense absorption occurs in the $3300 \mathrm{~nm}$ band followed by the $2200 \mathrm{~nm}$ band. The third most intense band in this region is $1650 \mathrm{~nm}$, as can be seen in Figure 1. In the proposed system, long distances may exist between sensors, then the best choice of the spectral region to be used is the band of $1650 \mathrm{~nm}$. This spectral region has the better cost-benefit between absorption spectral line intensity and lower optical attenuation in the fiber. Above $1700 \mathrm{~nm}$, optical fiber attenuation grows strongly and transmission distance is greatly reduced. Special fibers have been developed to transmit above 1700 $\mathrm{nm}$, however the maximum reach and its cost, compared with standard optical fibers, are prohibitive.

The proposed remote fiber optic methane leak detection system is better understood referring to Figure 2. In this system, an interrogation unit sends light pulses through the optical fiber and detects the backscattered light. Along the optical fiber, optical sensors detect the absorption of light due to presence of the methane. The sensors are placed in points of interest, such as valves, flanges, etc. The system comprises an interrogation unit, the sensors and optical fiber cable which has to be deployed along the pipeline. The expected system response is shown in the top of the figure where the blue curve is the reference signal and the red curve corresponds to methane detection in the fourth sensor. The reference curve is a typical OTDR trace obtained when the laser (LD) is tuned to a wavelength outside the absorption band of methane, while the red curve differs from the reference due to additional loss due to methane absorption when the LD is tuned to the absorption line of the gas (fourth sensor in this example). The interrogation unit and sensors are discussed in more detail in the following sub-sections.

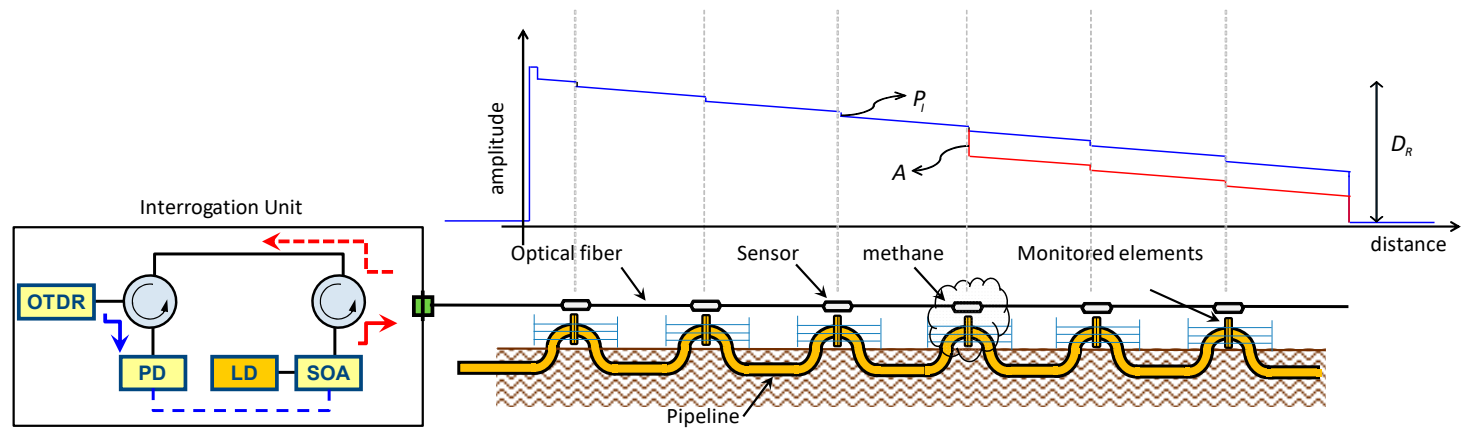

Figure 2. Proposed system for monitoring multiple points by a single optical fiber. System comprises an interrogation unit, the optical cable and the sensors. On top of the figure typical OTDR traces when the Laser Diode (LD) is tuned outside (blue curve) and inside (red curve) the absorption line of methane. 
To better understand the work principle, we refer to laboratorial results of Figure 3. In Figure 3a it is shown the collected OTDR traces varying the wavelength of the LD from 1645.50 to $1645.60 \mathrm{~nm}$ (by changing the current of the thermoelectric cooler). At a distance of $4 \mathrm{~km}$, a pure $\mathrm{CH}_{4}$ cell with optical path length of $5.5 \mathrm{~cm}$ and with 50 torr pressure is introduced. The obtained attenuation in the distance of $4 \mathrm{~km}$ is shown in Figure 3b. In this case of low-pressure pure methane, a double peak absorption spectrum appears in both the Hitran database [13] and in the experimental results. Also, the experimental data closely agrees with the expected attenuation obtained from the Hitran database proving that the proposed system properly works.
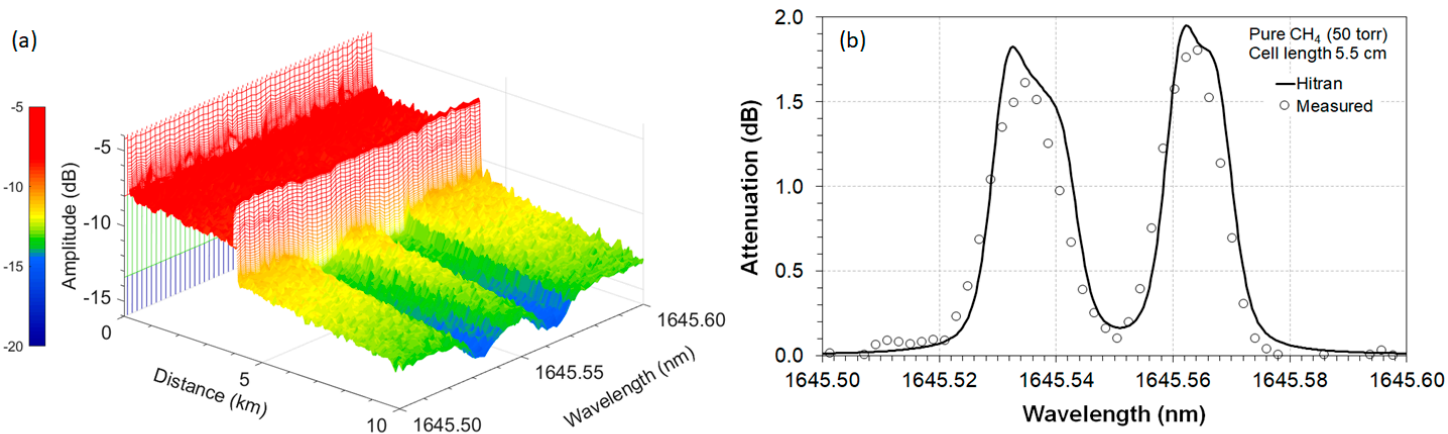

Figure 3. Laboratorial results for a setup with a pure methane cell with optical path length of $5.5 \mathrm{~cm}$ and 50 torr pressure is placed after $4 \mathrm{~km}$ from the interrogation unit. (a) collected OTDR traces varying the wavelength from 1645.50 to $1645.60 \mathrm{~nm}$, (b) the obtained attenuation in the distance of $4 \mathrm{~km}$.

For the field trial, the wavelength is not scanned but tuned in and out of the absorption band of the methane. Taken in account that, for a mixture of methane and air, a spectral broadening occurs [2], the LD is tuned in the center of the absorption spectrum at $1645.55 \mathrm{~nm}$ to obtain attenuation due to the methane and the LD is tuned to $1645.70 \mathrm{~nm}$ that is out of the absorption of methane in order to obtain a reference value. The tuning is accomplished by changing the current of the thermoelectric cooler. In Figure 4 it is shown the absorption spectrum from the Hitran database for a mixture of $1 \%$ methane in $\mathrm{N}_{2}$ for an optical cell of $10 \mathrm{~cm}$ length. Also shown is the comparison of the spectrum of pure vapor water (multiplied by 100) in order to discard the influence of environmental humidity on the system.

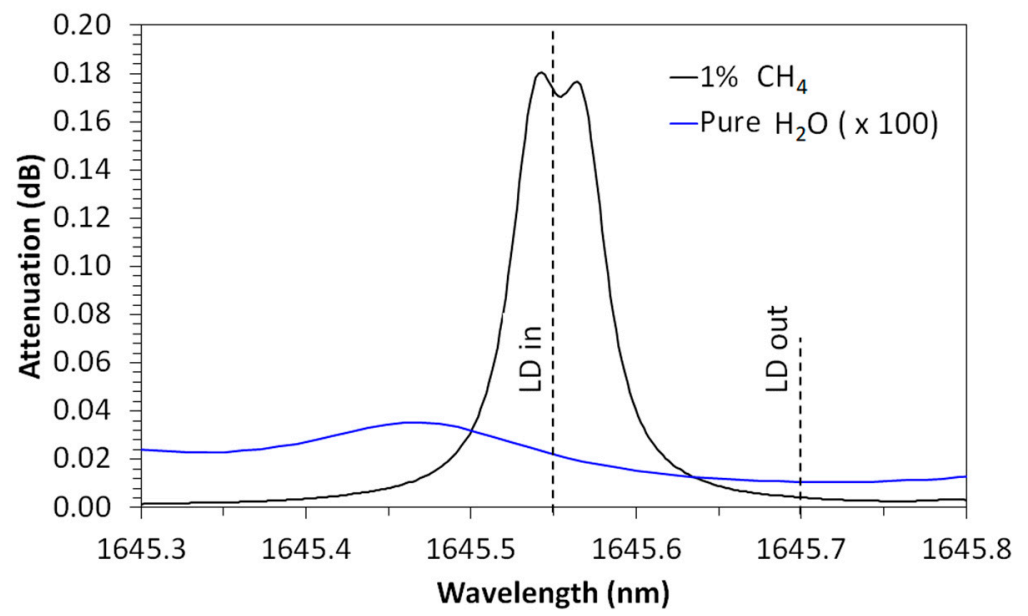

Figure 4. Absorption spectrum of $1 \%$ methane and pure water vapor (multiplied by 100 ) for a $10 \mathrm{~cm}$ optical path length. LD in and LD out of the methane absorption band also show.

As an example of real field result of the proposed system it is shown in Figure 5, the reference OTDR trace (blue curve) when the LD wavelength is tuned outside the absorption line of methane $(1645.70 \mathrm{~nm})$ and the measurement trace (red curve) when the LD is tuned inside the absorption line 
(1645.55 nm). In this figure, two sensors were placed at $\sim 5 \mathrm{~km}$ and $\sim 10 \mathrm{~km}$ of the interrogation unit. The sensors are measuring around $10 \%$ and $20 \%$ of methane concentration, respectively. The reference trace is so called as it measures a reference trace of attenuation versus distance outside the absorption line and thus without the influence of gas. This reference is used to calculate the methane absorption by compensating attenuation due to fiber itself.

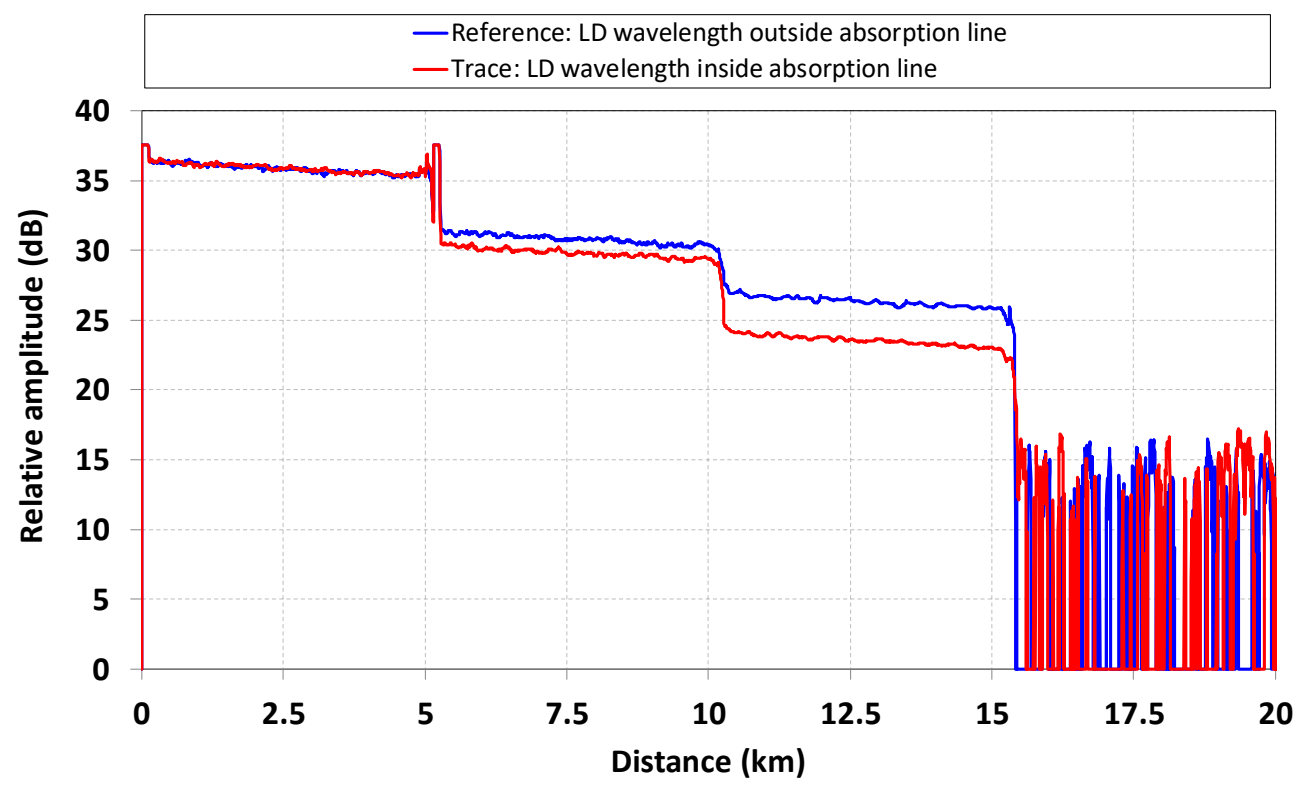

Figure 5. Example of real field results based in the proposed system. Reference OTDR trace (blue curve) and measurement trace (red curve) corresponds to the case of LD wavelength tuned outside and inside the absorption line of methane, respectively. Sensors are placed at $\sim 5 \mathrm{~km}$ and $\sim 10 \mathrm{~km}$ of the interrogation unit. LD inside absorption line (1645.55 nm), LD outside absorption line (1645.70 nm).

\subsection{Interrogation Unit}

The interrogation unit is the core of the system. It can be better understood following the schematic box depicted in Figure 2. The interrogation unit uses a distributed feedback laser (LD) that is operated in continuous wave $(\mathrm{CW})$ regime. The $\mathrm{LD}$ wavelength is tuned by properly driving a thermoelectric cooler (TEC). The thermistor temperature of the LD is linearly related to the wavelength and it is used to correctly establish the wavelength of emission. A commercial OTDR module is used to generate an optical pulse with typical pulse widths and repetition rates. The optical pulse, typically at $1550 \mathrm{~nm}$, is deviated by an optical circulator and detected by a photodetector (PD). The optical pulse is used to modulate a semiconductor optical amplifier (SOA) by proper electronic circuitry. The SOA operates in the $1650 \mathrm{~nm}$ window and is fed by the CW light of the LD. The SOA not only modulates the LD light, but also amplifies the LD power and avoids the broadening of the laser linewidth.

Thus, a pulsed optical signal with reduced linewidth is sent through another optical circulator to an optical fiber (of a cable which follows a pipeline, for example) where several optical cells sensors are placed in series along the optical fiber. These sensors are common direct absorption fiber optical cells containing fiber optical collimators at input and output and a chamber where gas interact with the light.

The Rayleigh backscattering which comes from the optical link is deviated by the two optical circulators and detected by the same OTDR device resulting in an OTDR trace as depicted on the top of Figures 2 and 5. For each sensor, an insertion loss $\left(P_{I}\right)$ is observed due to optical losses related to the beam expansion to the cell and collimation to the fiber core. When a methane leakage occurs near to the sensors, an additional loss $(A)$ is observed when LD is properly tuned to one of the absorption lines 
of methane. This additional loss is related to the methane concentration in the optical cell sensor by the well-known Beer-Lambert law [14], the expression of which can be re-written as:

$$
A=a L C
$$

where $A$ is the additional loss, $a$ is the absorption coefficient here expressed in $\mathrm{dB} /(\mathrm{ppm} \mathrm{m}), L$ is the optical cell length, and $C$ is the gas concentration.

When the LD wavelength is scanned within few nanometers, the absorption spectrum can be obtained for each one of the sensors cells. Alternatively, the LD wavelength is tuned alternately to coincide with the absorption line of methane and outside the selected absorption line in order to obtain a reference trace.

The interrogation unit is shown in Figure 6. The external dimensions are $440 \mathrm{~mm} \times 240 \mathrm{~mm} \times 90 \mathrm{~mm}$. The interrogation unit has ethernet connection as well as USB and SD ports, which can be used to transmit data, also recorded in a SD card. The interrogation unit is designed so that the monitoring software can be executed without the need of a dedicated external computer in automatic or manual mode, through remote access via an ethernet network. Access through an auxiliary computer is only necessary for the calibration and maintenance of the interrogator. The Colibri ${ }^{\mathrm{TM}}$ iMX6 SoC (System on Chip), developed by Toradex, was used as internal onboard computer. This system consists of a small size card with an NXP i.MX6 microcontroller, provided with Linux operating system. As built-in oscilloscope, the interrogation uses a commercial OTDR module (Anritsu MW9077A) which has the advantage of generating optical pulses of proper temporal width and with appropriate duty-cycle. In addition, the OTDR module is capable of translating backscattered light in OTDR traces with relative amplitudes expressed in $\mathrm{dB}$ and distances, in kilometers $(\mathrm{km})$. The electrical and optical components of the interrogation unit can be seen in Figure 6.

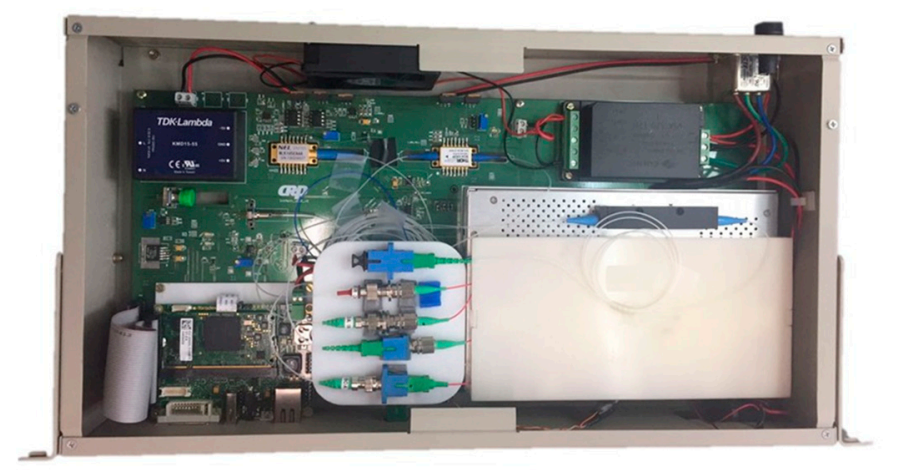

Figure 6. Interrogation unit: top view of electrical and optical components.

\subsection{Sensor Units}

The principle of operation of optical sensors is the direct absorption of the light by a gas. Thus, sensors consist of a pair of optical collimators at input and output fibers and a chamber where gas interact with the light. The specific sensors developed for the system use small optical cells with length of $50 \mathrm{~mm}$ and $5 \mathrm{~mm}$ diameter as shown schematically in Figure 7a. In Figure 7b the actual compact optical cells are shown. Multiple optical cells are used together to increase sensitivity of the sensor (e.g., four optical cells are four times more sensitive than one), however a trade-off exists due to the fact that each optical cell has an intrinsic loss $\left(P_{I}\right)$ and the use of more optical cells in the sensor head will increase the final value of the overall intrinsic loss at spences of achieved distance range. 
(a)

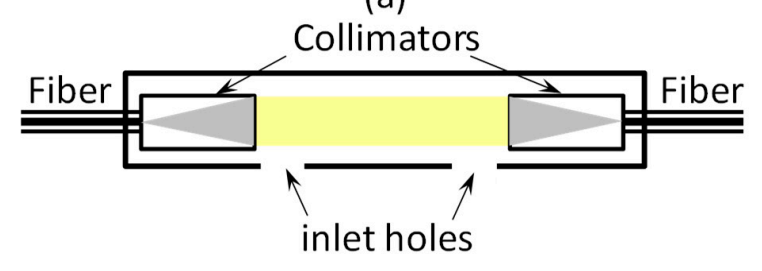

(b)

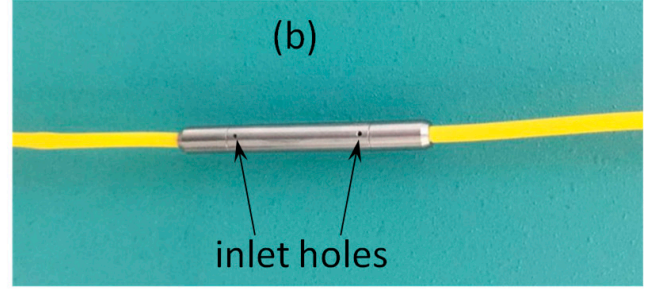

Figure 7. Sensor elements. (a) Schematic of the compact optical gas cell. (b) View of the actual compact optical gas cell used in the prototypes, $50 \mathrm{~mm}$ long and $5 \mathrm{~mm}$ diameter.

The sensors were developed in order to: (i) be easy to install, (ii) mitigate the action of the wind, (iii) let methane free to disperse in the atmosphere and (iv) be adaptable to a number of leak points (valves, vents, flanges, connectors, pumps, etc.). The sensors are divided in two main parts: the sensor head and an external package. The sensor head is composed of four small optical cells in two configurations shown in Figure 8a,b. The external package is used to protect the sensor head from the action of the wind, dust, temperature, as shown in Figure 8c,d for application in the vent valve and a small flange. We stress that with this conception it is easy to modify the sensor package to any possible application and dimensions, mainly if the external package would be re-designed.

(a)

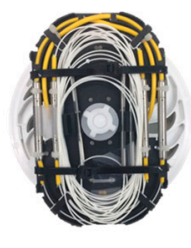

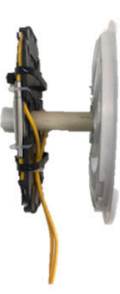

(c)

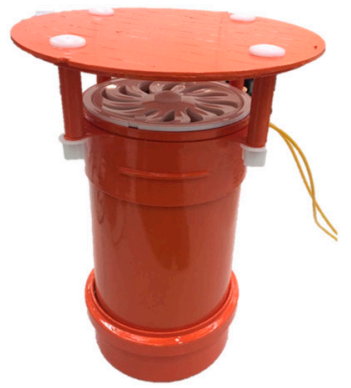

(b)
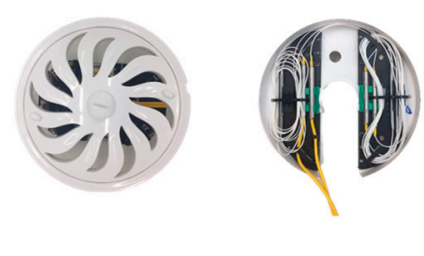

(d)

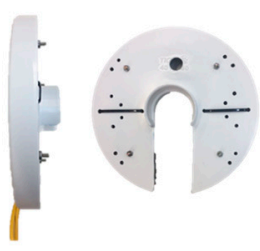

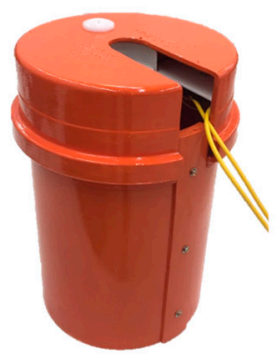

Figure 8. Developed sensor units. (a) sensor head for flange application, (b) sensor head for vent valve application, (c) sensor head with external package for flange application, (d) sensor head with external package for vent valve application.

\section{Calibration and Uncertainty Analysis}

Prior to the field installation, a calibration of the system was performed. The calibration data is shown in Figure 9 for the specific sensor head with total optical path length of $10 \mathrm{~cm}$ cell (4 compact cells). To measure the methane concentration, commercial equipment was used (Detecto Pak-Infrared DP-IR ${ }^{\mathrm{TM}}$ from Health Consultant, https://heathus.com/, Houston, USA). 


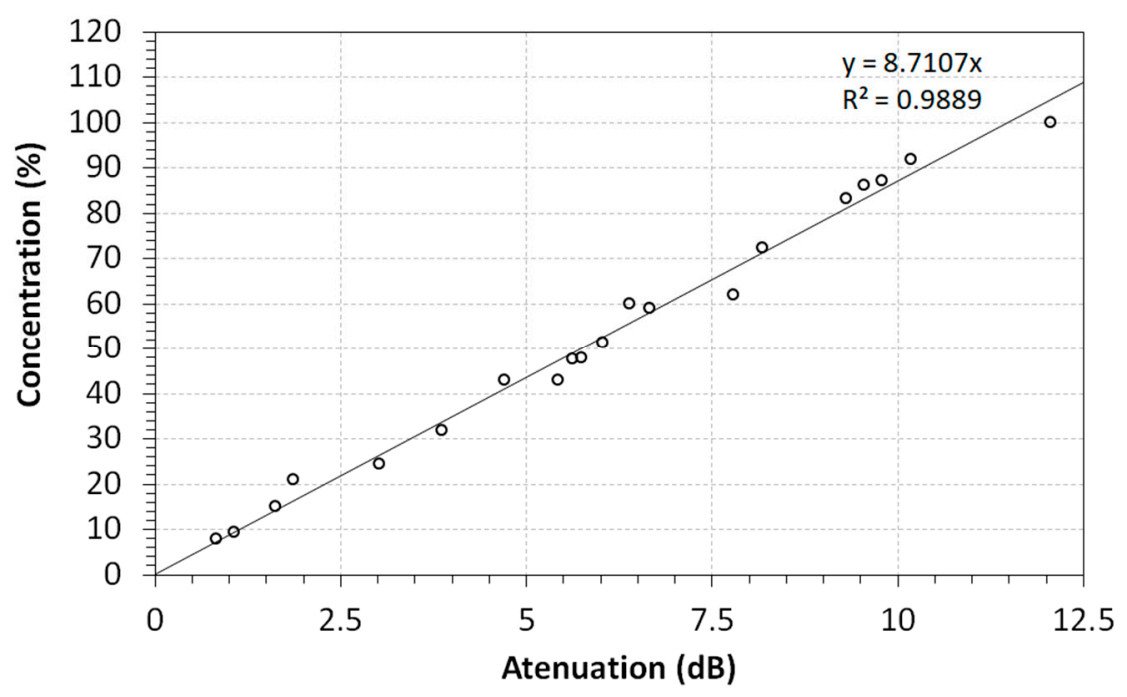

Figure 9. Calibration curve of the proposed system using commercial equipment DP-IR from Health-Consultant.

According to the Beer Lambert Law re-written as in (1) the gas concentration is obtained from the Equation (2):

$$
C=\frac{A}{a L}
$$

The expression of error propagation of (2) is given by (3):

$$
\sigma_{C} \frac{\sigma_{A}}{a L}
$$

where $\sigma_{A}$ and $\sigma_{C}$ are the errors (uncertainties) in the attenuation and in the concentration.

The attenuation error $\sigma_{A}$ has two components: a component corresponding to the attenuation error deriving from the laser stability in the absorption line $\sigma_{L}$ and another component corresponding to the determination of the attenuation gap in the OTDR trace by the linear adjustment method in the OTDR curve, $\sigma_{\text {OTDR }}$. Specifically, the first error comes from the residual displacement at the wavelength of the laser when it is tuned at the absorption peak. A small wavelength deviation results in slightly different absorption and therefore an error in determining the attenuation. On the other way the error of the gap determination (insertion loss) of attenuation is essentially due to noise factors in the OTDR trace.

The relation between the errors $\sigma_{A}, \sigma_{L}$ and $\sigma_{O T D R}$ can be written as (4):

$$
\sigma_{A}=\sqrt{\sigma_{L}^{2}+\sigma_{O T D R}^{2}}
$$

where in our case the $\sigma_{O T D R}$ and $\sigma_{L}$ are $0.05 \mathrm{~dB}$ circa resulting in $\sigma_{A}=0.07 \mathrm{~dB}$.

From Figure 9 and (2) it can be seen that $\frac{1}{a L}=8.71$ and thus from (3) $\sigma_{C}=0.6 \%$. Thus when one reads $2 \%$ of methane in the proposed system this would be understood as $2.0 \pm 0.6 \%$.

For the present application and demonstration of equipment the above uncertainty is enough, as can be inferred from high concentrations detected in the field. We also note, as can be inferred from (3), that this uncertainty can be greatly reduced by increasing the cell length. Indeed, the value of $\sigma_{C}$ reduces to $0.06 \%$ for a $1-\mathrm{m}$ long cell. Also, a better laser stability and data acquisition of the OTDR traces would further reduce this uncertainty.

\section{Installation of the System in Field}

The test field place was selected from the plants of a Brazilian oil and gas transportation company (Transpetro). Initially some natural gas transportation pipelines were selected at a site near São Paulo. 
The state of São Paulo was chosen because of its important natural gas pipeline network, with a highly integrated transmission and distribution grid. In addition, the site selected would have sufficient infrastructure to install the system, including a constant supply of electric energy, proper refrigeration, and Ethernet access. Among these requirements, we add the fact that fugitive emissions of methane were reported to occur mostly in compressor stations and delivery stations accounting for $21.5 \%$ and $10.1 \%$ of total fugitive emissions of methane in the U.S, respectively [15]. Accordingly, the compressor station was selected due to all the above requirements in the city of Taubaté. For the pipeline site selected, a methane fugitive emission survey was made to identify leaks with a portable infrared detection device, DP-IR ${ }^{\mathrm{TM}}$. At the compressor station selected, two methane leak points were found: site 1 was a flange on a derivation of pressure instrumentation and site 2 was a vent valve. The field-test location is shown in Figure 10a with the sensor sites, and the interrogation unit site is also indicated in this figure. Site 1 is one flange on a derivation of pressure instrumentation, site 2 is one vent valve and site 3 is the shelter of the compressor station where the interrogation unit was installed. In Figure 10b it is also shown the distance from compressor station to the weather station of approximately $8 \mathrm{~km}$.
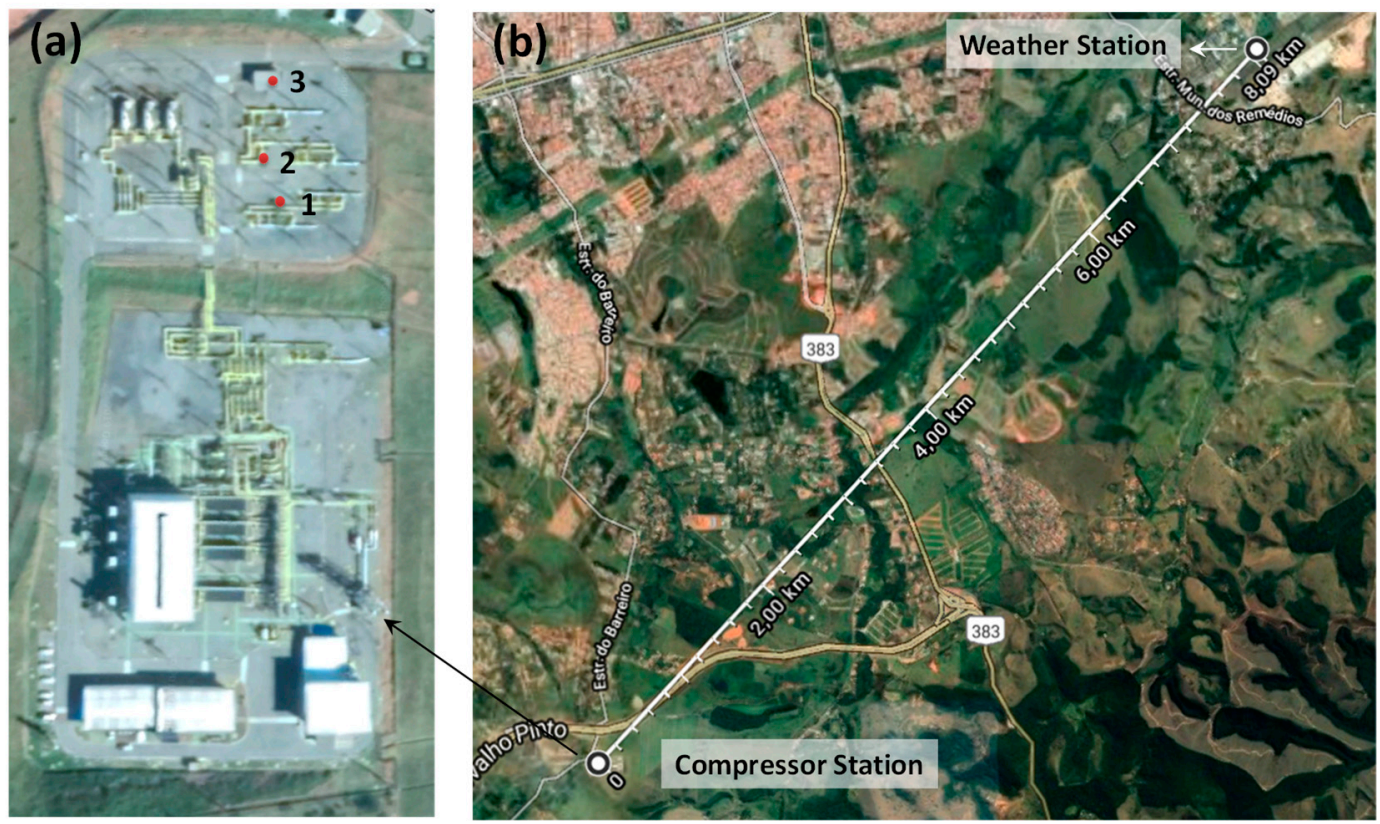

Figure 10. Installation of the remote fiber optic methane leak detection system and distance from a weather station: (a) view of the compressor station with indicated points of installation, (b) distance from compressor station to weather station of $\sim 8 \mathrm{~km}$ (Google Maps 2019).

In Figure 11 we show sites 1 and 2 of the compressor station chosen as points to be monitored. In Figure 11a it is shown the flange on a derivation of pressure instrumentation. At the left of the Figure 11a is shown the flange without sensor and at the right of Figure 11a is shown the sensor already installed. The procedure of installation was very quick, taking only few seconds as can be seen in Video V1. The external package was just placed in position and a bottom cap was used to fix this external package. The sensor head was then placed on top of the external package and finally it was applied a roof to protect from wind. In this way the whole flange was involved with the sensor, so methane can flow to the atmosphere through the openings of sensor head. In this path, methane enters the small inlet holes of the optical cells. As mentioned before, in principle this proposed sensor can be used in a variety of places of interest employing the same sensor head and changing the external package form and dimensions. In fact, the same package and sensor head shown in Figure 8a could be used in the second monitored point in this field test, a vent valve shown in Figure 11b-left. In this case, the package and sensor should be placed horizontally. However, we opted to design a new sensor head and external package as shown in Figure $8 \mathrm{~b}$ to prove the easy adaptability of this sensor concept. In 
this situation, the sensor was placed vertically involving all the lower vent valve of interest. The sensor head has a U-design that enables it to be placed just above the point to be monitored. The procedure of installation is very similar to the previous example. First, the external packaging was fixed around the lower valve of the vent and the sensor head was placed on top of it. After that, a cap and roof placement complete the installation steps. Figure 11b-left shows the sensor completely installed in the lower vent valve of interest. The sensors are also easy to remove for operation or maintenance.

(a)

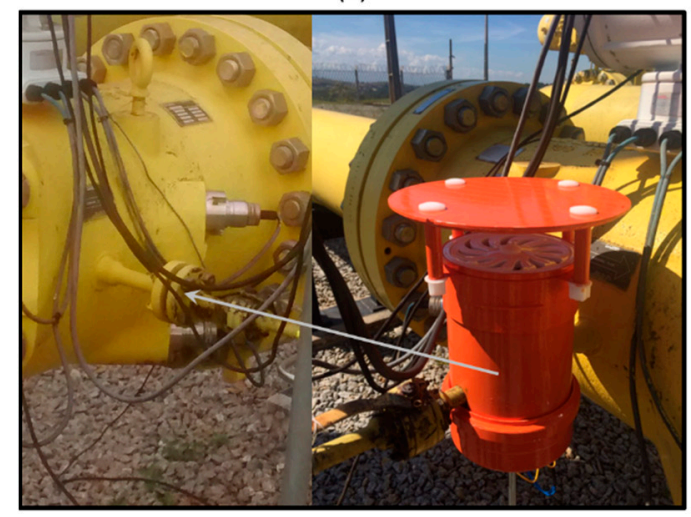

(b)

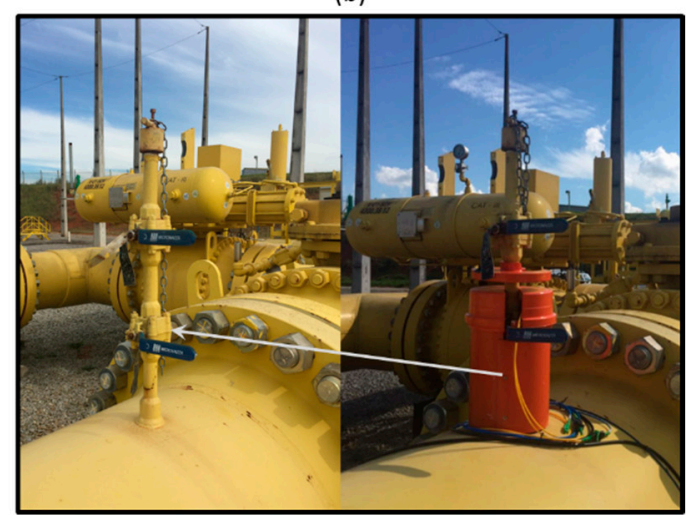

Figure 11. Sensor units installed in the two points of interest. (a) Flange on a derivation of pressure instrumentation (sensor 1 ) and (b) vent valve (sensor 2).

Again, we remember that sensors conceived with the separation of the optical sensor head and external package can be used and adapted to any kind of suspect point of fugitive emission, such as valves, flanges, connectors, and pumps among others. In a practical application in a compressor station many points can be monitored with sensors of this type. Actually, compressor stations at different geographic locations can be monitored by the proposed system, provided that there are optical fiber cables deployed in those places.

The interrogation unit was installed in the shelter of the compressor station at site 3 of Figure 10a in a distance of approximately 100 meters from the sensors. In order to simulate the long-distance application, such as pipelines, the interrogation unit's rack had three optical fibers spools of $5 \mathrm{~km}$ protected by plastic boxes. In the Video V2 it is shown the screen of the system with OTDR traces of reference and measurement as well as the concentrations measured by sensors 1 and 2 .

\section{In-Field Comparison of the System with Commercial Equipament}

In a previous visit to the compression station, a comparison of the system with the commercial equipment (DP-IR) was performed in the field. A compact version of the sensor was used in that occasion in the vent valve. This compact version of the sensor was composed of just one optical cell without the present package, as can be seen in Figure 12a. The commercial gas inlet was placed just above the sensor in order to capture almost the same methane amount as the optical sensor. The results are shown in Figure 12b. As can be seen a good agreement is observed between the two systems which translates in confidence of the proposed system. 

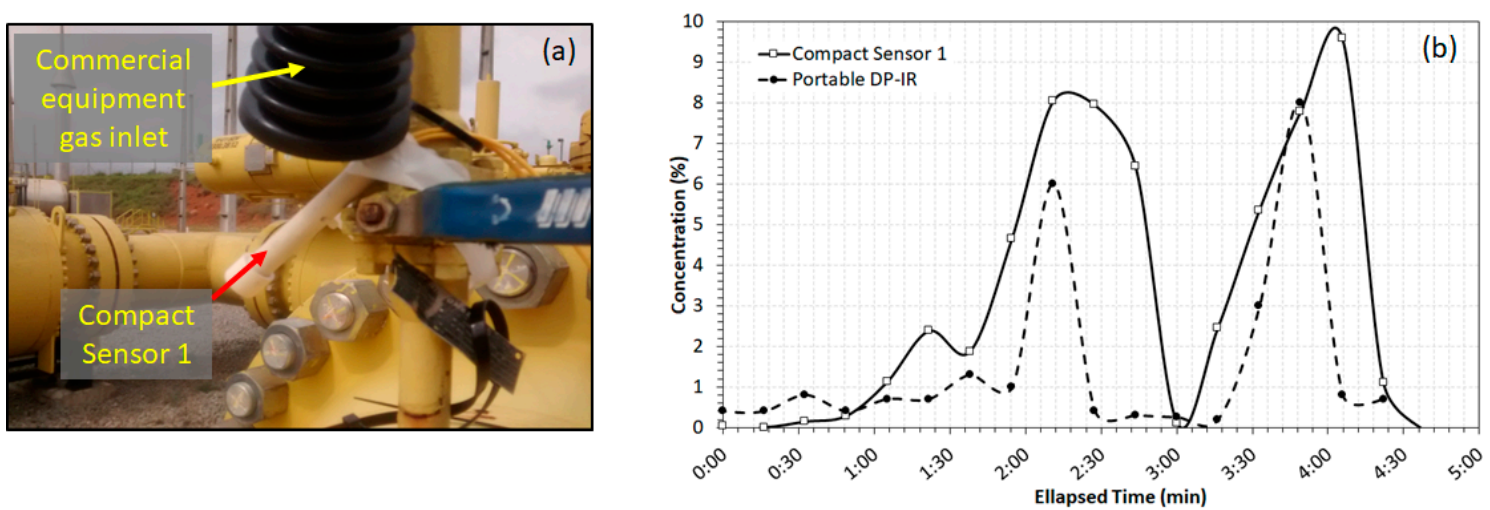

Figure 12. In-field comparison of the proposed system with a commercial equipment model DP-IR from Health Consultant. (a) view of the performed test with gas inlet of commercial equipment just above the used compact sensor, (b) test showing good agreement between the two systems.

\section{Results and Discussion}

The data that was gathered from April 4, 2017 to July 15, 2017 are shown in Figure 13 and compared with meteorological data obtained from a weather station of the Brazilian National Institute of Meteorology (INMET) nearest the Taubaté compressor station. The data of the meteorological parameters of the station were obtained from the website of the Brazilian National Meteorological Institute [16]. From the various meteorological data available, namely: temperature, humidity, dew point, pressure, wind velocity, radiation and rainfall, only temperature, wind speed and humidity are shown in Figure 13. The first two showed greater influence on the value of the measured concentrations.

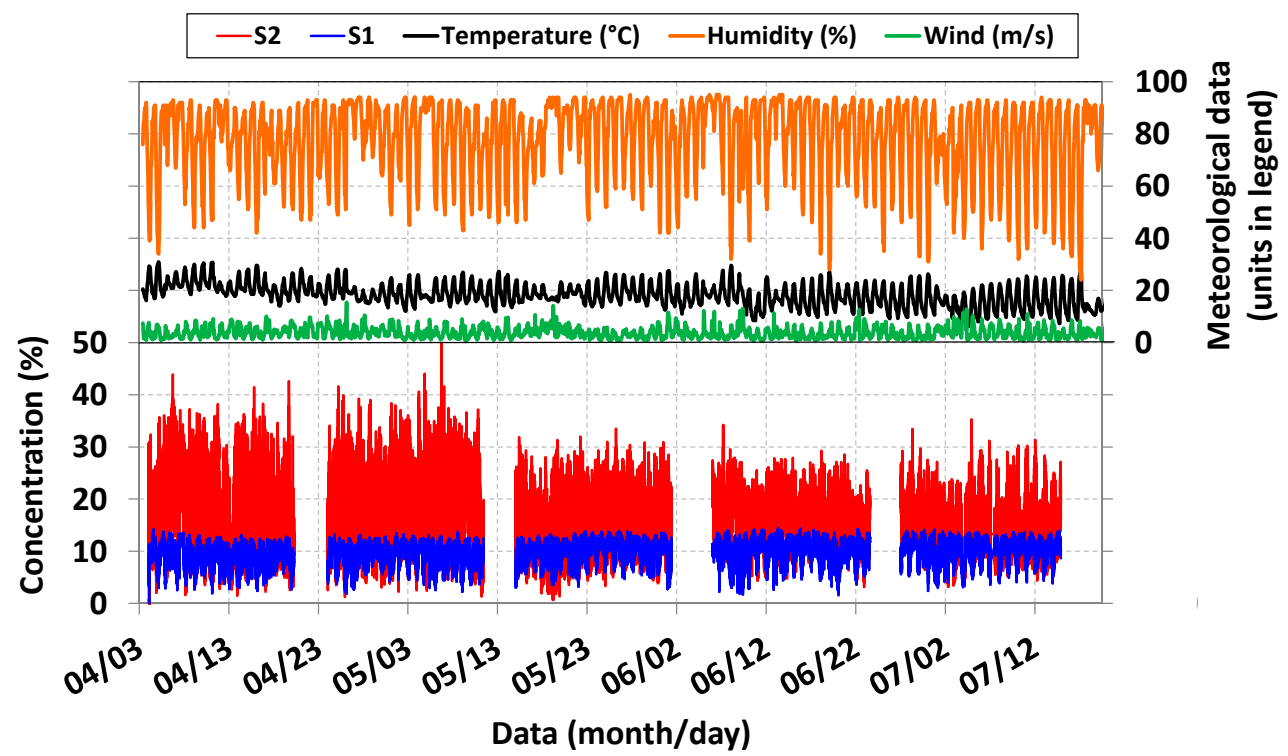

Figure 13. Comparison between methane concentration for sensors S1 and S2 and meteorological data.

During this analyzed period, it was observed that the system stopped the data collection after a period of 15 to 20 days, accusing an error of lack of space in the flash memory of the device (memory of the shipped computer). Some attempts to find out the cause of this interruption have been made, but it is still unclear what is causing the error. During the laboratorial tests this problem was not detected because the system did not operate for so long uninterrupted. For a correction of this bias, local monitoring is necessary at the moment the error occurs, which was impracticable during the field test. It was decided to leave the system working in this way with periodic restarts during data 
collection. In this way, five sets of data were acquired during this period as shown in Figure 13. The five sets of data refer to the periods:

- $\quad 1^{\text {st }}$ data set: from April 4 to April 20, 2017;

- $\quad 2^{\text {nd }}$ data set: from April 24 to May 11, 2017;

- $\quad 3^{\text {rd }}$ data set: from May 15 to June 1, 2017;

- $4^{\text {th }}$ data set: from June 6 to June 24,2017 , and

- $\quad 5^{\text {th }}$ data set: from June 27 to July $17,2017$.

Still analyzing Figure 13, we observed, from the results, that the system detected the presence of methane in the two installed sensors. Sensor 1 recorded concentrations between $2.5 \%$ and $15 \%$, and sensor 2 recorded concentrations of $5 \%$ to $30 \%$ It can be noted that during the period analyzed the variation in these recorded concentrations showed a periodic behavior (notably in sensor 1) some correlation with the variation of ambient temperature and with the action of the wind. To better determine this influence with the meteorological parameters it was verified that it is necessary to use moving averages in the collected data. If we consider the first set from April 4, 2017 until April 20, 2017 , we noticed that by varying the number of means it is possible to observe a correlation between the wind velocity, for example, and the methane concentration measured by the sensors. In Figure 14a we presented the untreated concentration data and in Figure $14 \mathrm{~b}-\mathrm{d}$ the number of moving averages applied were 10, 20 and 40 respectively.
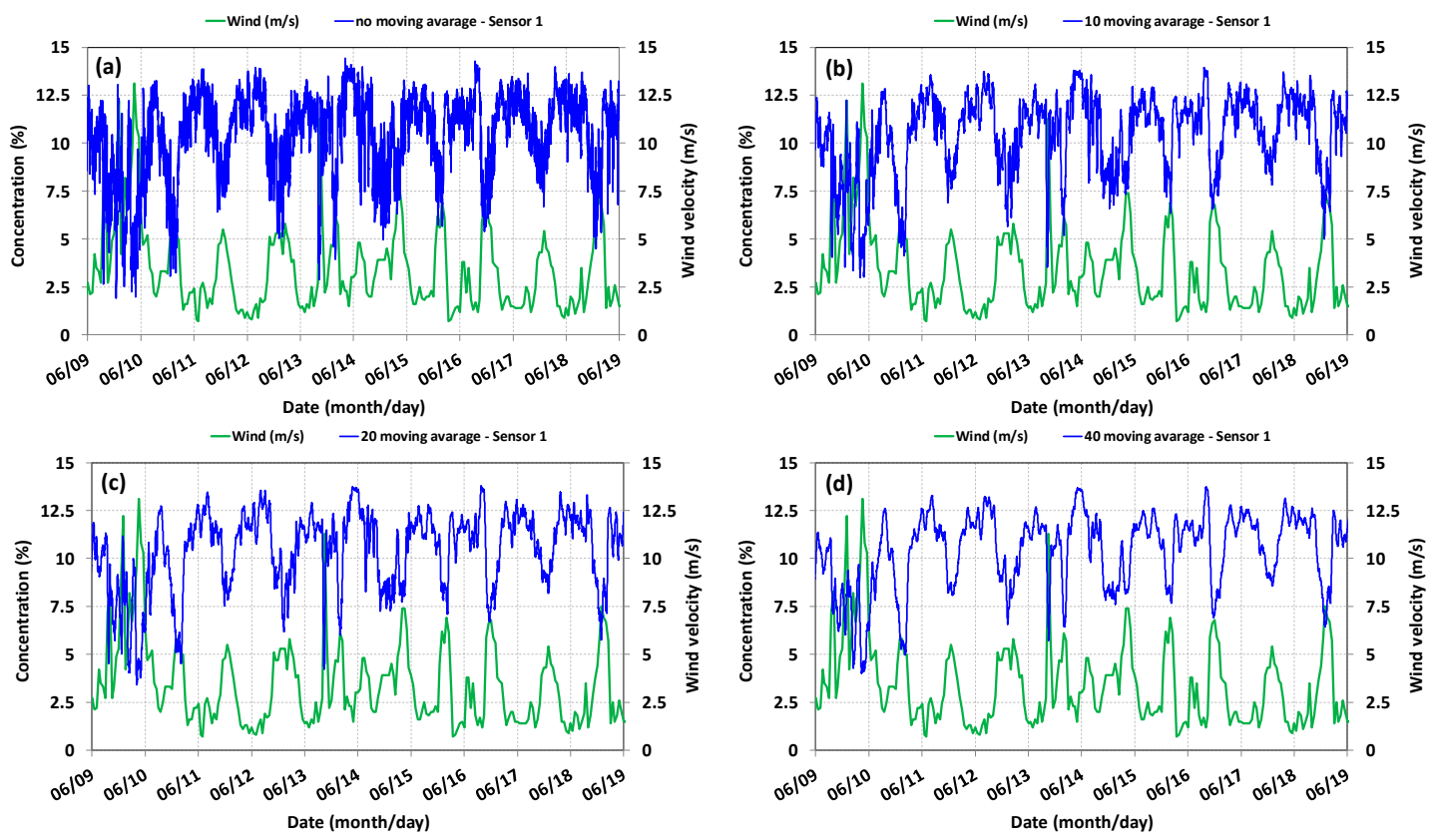

Figure 14. Increase of moving averages for observation of correlation between concentration data and climatic data. (a) untreated concentration data, (b) 10 moving averages applied to sensor 1 data, (c) 20 moving averages and (d) 40 moving averages.

In Figure 14 we observed that as the number of moving averages increases, it becomes more visible that the value of the methane concentration increases with the lower incidence of wind velocity on the sensor and vice versa. This result was already expected, since the use of the wind bar element in the sensors does not completely prevent the wind from acting on the sensor.

The reason why this correlation is evident is due to the acquisition time of the methane monitoring system. In fact, the system collects a concentration value approximately every $1.5 \mathrm{~min}$. Weather data is available every hour. The mean of 40 concentration values corresponds to the average value of 1 hour $(40 \times 1.5$ minutes) of measurement and this is why Figure $14 \mathrm{~d}$ has a clearer correlation than the others. 
A more detailed analysis of the correlation with the meteorological data was carried out, we focused on the correlation with the wind velocity and with the ambient temperature, which showed more dependence with the registered concentration values. It was necessary to treat the concentration data, to apply smoothing algorithms of moving averages and to equalize the temporal data, so that a concentration value coincides in time with the corresponding value of the meteorological parameter. This treatment must be performed in order to calculate the correlation between the variables (concentration versus wind speed and concentration versus temperature).

It is possible to observe in Figure 14 that there is a negative correlation for sensor 1 with respect to the wind, that is, the increase of wind speed reduces the concentration of methane gas in the sensors, as expected. However, it is not possible to quantify this correlation using these graphs, but they provide an important visual aid. The same negative correlation pattern repeats to the other sensor and with temperature.

In order to quantify the correlation of the above climatic data, we make use of the Pearson correlation $[17,18]$. Pearson's correlation coefficient measures the degree of correlation (and whether it is positive or negative) between two variables. This coefficient, represented here by $r$, assumes only values between -1 and 1 . In the case where $r=1$ there is a perfect positive correlation between the two variables, since when $r=-1$ there is a perfect negative correlation between the two variables, that is, if one increases the other always decreases. The case where $r=0$ means that the two variables do not depend linearly on each other (see Figure 15). However, there may be a nonlinear dependency. Thus, the result $r=0$ must be investigated by other means. Intermediate values reflect the degree of correlation between the variables under analysis, which can be further classified according to [17,18]. Here we adopt the classification given by [17]:

- 0.9-1: positive or negative indicates a very strong correlation.

- 0.7-0.9: positive or negative indicates a strong correlation.

- 0.5-0.7: positive or negative indicates a moderate correlation.

- 0.3-0.5: positive or negative indicates a weak correlation.

- 0-0.3: positive or negative indicates a negligible correlation.

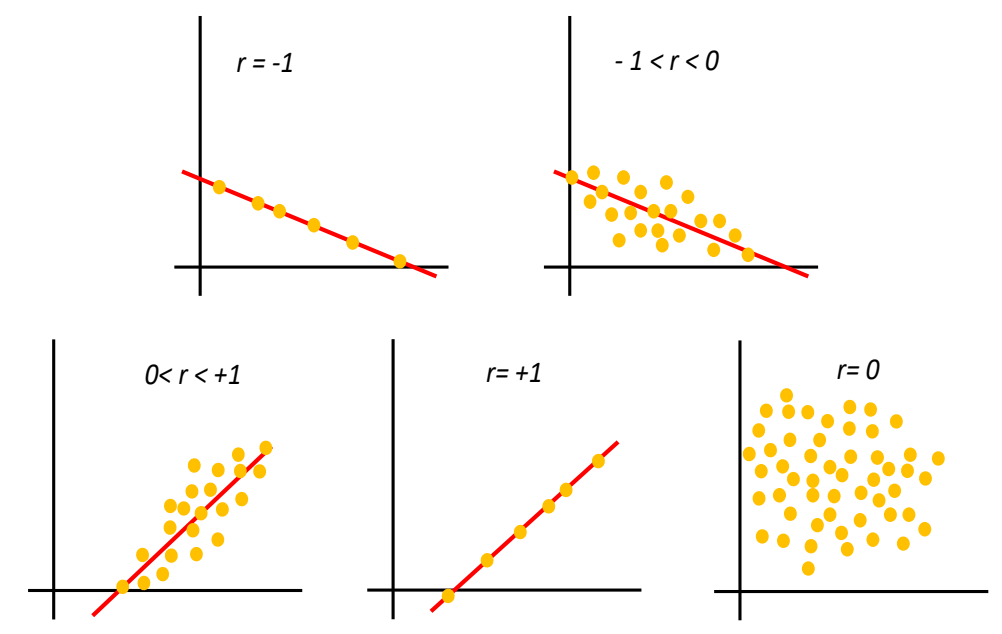

Figure 15. Examples of dispersion diagrams with different values of $r$ (correlation coefficient) [19].

Some of the plots of the linear regression employed are shown in Figures 16-18. In Figure 16, we show the case of the correlation between the concentration measured by sensors 1 and 2 and the wind velocity obtained from the climatic station for the 3rd set of data from May 15 to June 1, 2017. The obtained correlation is moderate for both sensors. This indicates that even with the use of the external package to protect the sensor head from the action of the wind influence of this environmental effect is still present. 

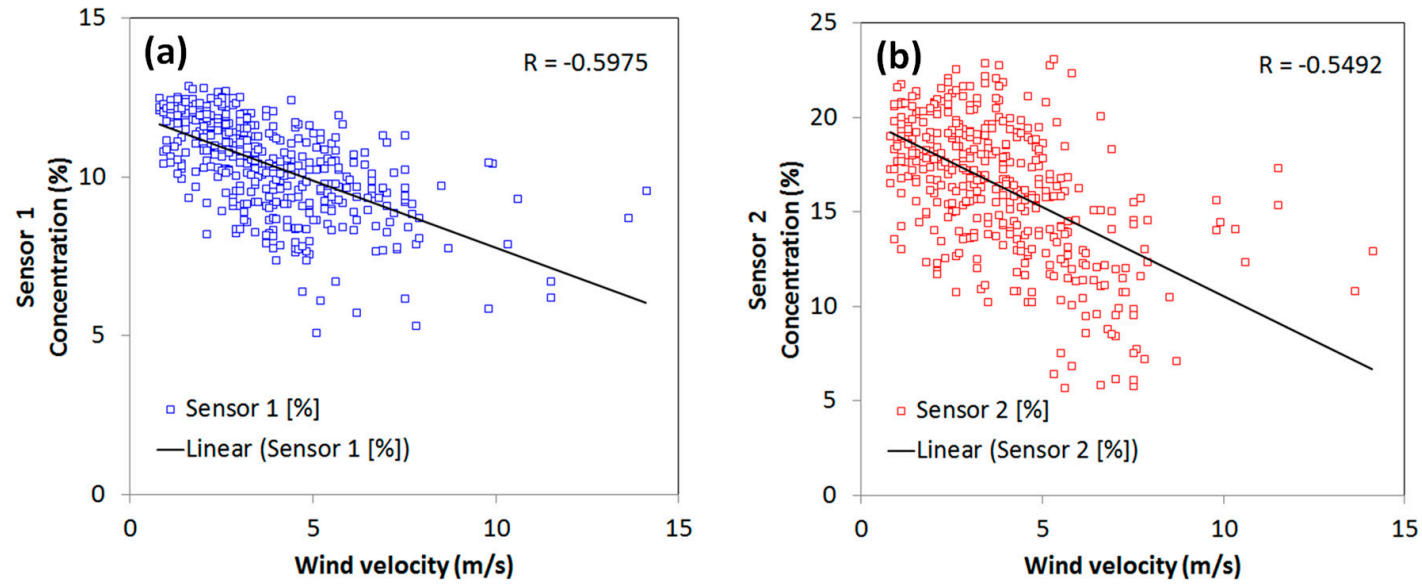

Figure 16. Correlation between the concentration measured by sensors 1 and 2 and the wind velocity obtained from the climatic station for the 3rd set of data from May 15 to June 1, 2017. (a) Sensor 1, (b) sensor 2 .
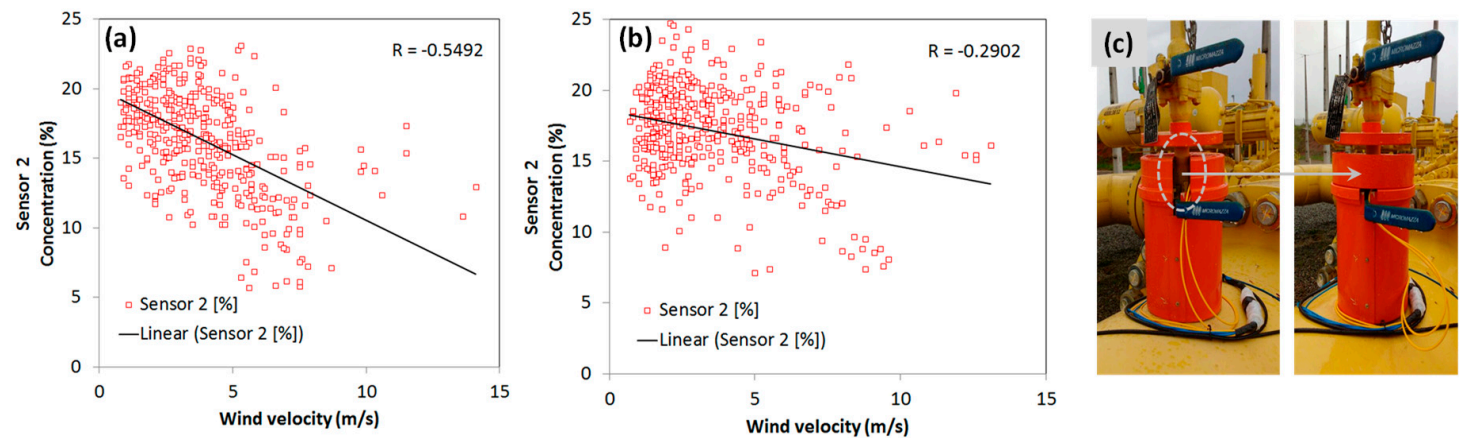

Figure 17. Correlation between the concentration measured by sensor 2 and the wind velocity obtained from the climatic station. (a) 3rd data set from May 15 to June 1, 2017, (b) 4th data set from June 6 to June 24, (c) modification introduced in sensor 2 to reduce wind action.
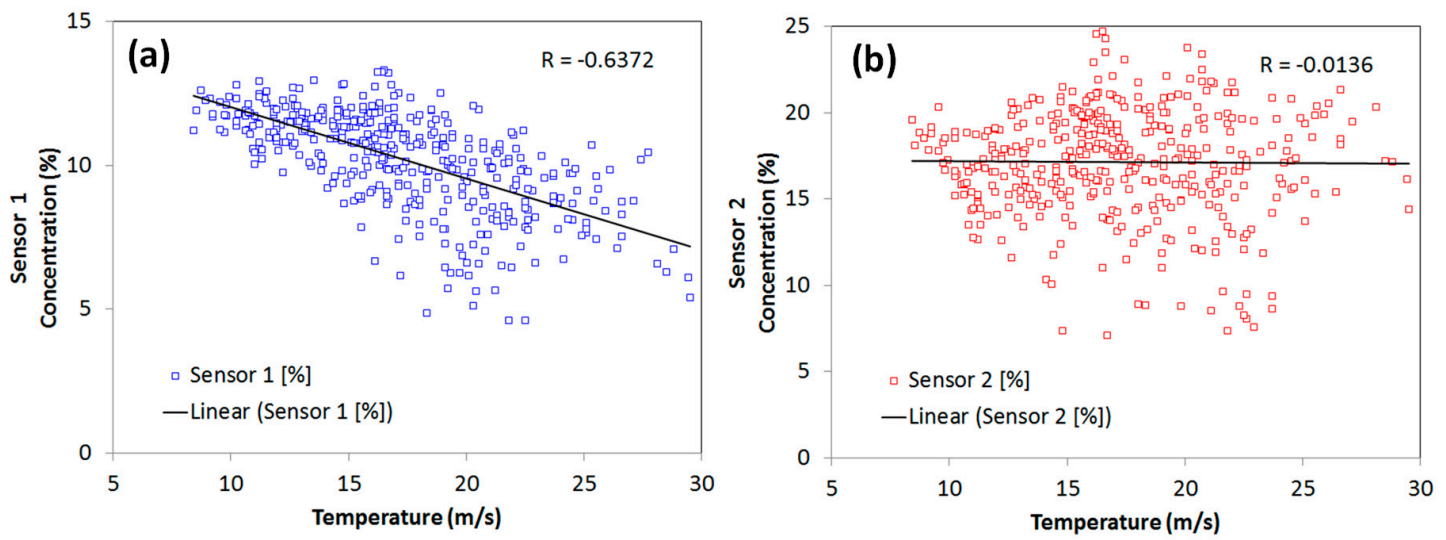

Figure 18. Correlation between the concentration measured by sensors 1 and 2 and the temperature: (a) sensor 1 (moderate correlation) and (b) sensor 2 (negligible correlation).

Another interesting example obtained from this correlation analysis is shown in Figure 17. In this figure, linear regression for sensor 2 concentration as a function of wind velocity is shown for the 3rd data set (from May 15 to June 1), Figure 17a and for the 4th data set (from June 6 to June 24), Figure 17b. As can be seen the Pearson coefficient increased from -0.55 to -0.29 , that is, changing from moderate to negligible negative correlation. This indeed results from a modification introduced in sensor 2 to reduce wind action, as shown in Figure 17c. 
As yet another example of the correlation analysis we show in Figure 18 the example of the $4^{\text {th }}$ data set from June $6^{\text {th }}$ to June $24^{\text {th }}, 2017$. In this case, correlations of sensors 1 and 2 with temperature are show. In Figure 18a it is shown that sensor 1 presents moderate negative correlation while in Figure $18 \mathrm{~b}$ it is shown that sensor 2 presents negligible correlation with this meteorological data.

We applied the correlation analysis to all five sets of data of Figure 13. It is possible to observe that all the correlations obtained are negative except in cases where the correlation is very close to zero, that is, in cases in which there is no linear correlation between the concentration of the sensors and the temperature. We also note that, for this case, sensor 2 has a negligible correlation with temperature and in most cases the value is very close to zero. On the other hand, sensor 1 presented negligible correlation with temperature only for the 1st set of data, in the others the correlation was moderate and negative. One hypothesis for this behavior is that sensor 1 (which is on the flange in the pressure instrumentation shunt) is more protected from the action of the wind, whereas the sensor 2 (located in the vent) is exposed to the wind action and therefore presents greater heat exchange with the environment without local heating. This hypothesis could be proven if temperature sensors were installed in place on each sensor, i.e., the comparison should be made with localized temperature measurements. It is believed that the reason for varying the concentration measured due to temperature comes from the gas equation, $\mathrm{PV}=\mathrm{n} \mathrm{RT}$, in this case $\mathrm{P}$ is practically constant, varying throughout the period of 0.021 atmospheres (corresponding to $2.2 \%$ of the mean of recorded pressures) and $\mathrm{V}$ is the volume of the compact optical cells. The only variables would be $\mathrm{n}$ and $\mathrm{T}$ and, therefore, an increase in temperature, corresponds to a decrease in number of molecules (mols), n, in the optical cell, and consequently a decrease in concentration, that is negative correlation.

Another environmental data analyzed was the humidity. Humidity has strong correlation with the temperature, as can be observed in the Figure 19. In Figure 19a temporal evolution of both meteorological parameters is presented, while in Figure 19b the Pearson correlation parameter is calculated for the time period shown. We believe that the high temperature causes the low humidity. In fact, in the spectral region from 1645.3 to $1645.8 \mathrm{~nm}$ there is no significant absorption of the $\mathrm{H}_{2} \mathrm{O}$ (Figure 4) and thus it's not detected by the proposed system. This ultimately indicate that variations of sensor 1 and sensor 2 comes from temperature and not from the humidity itself.
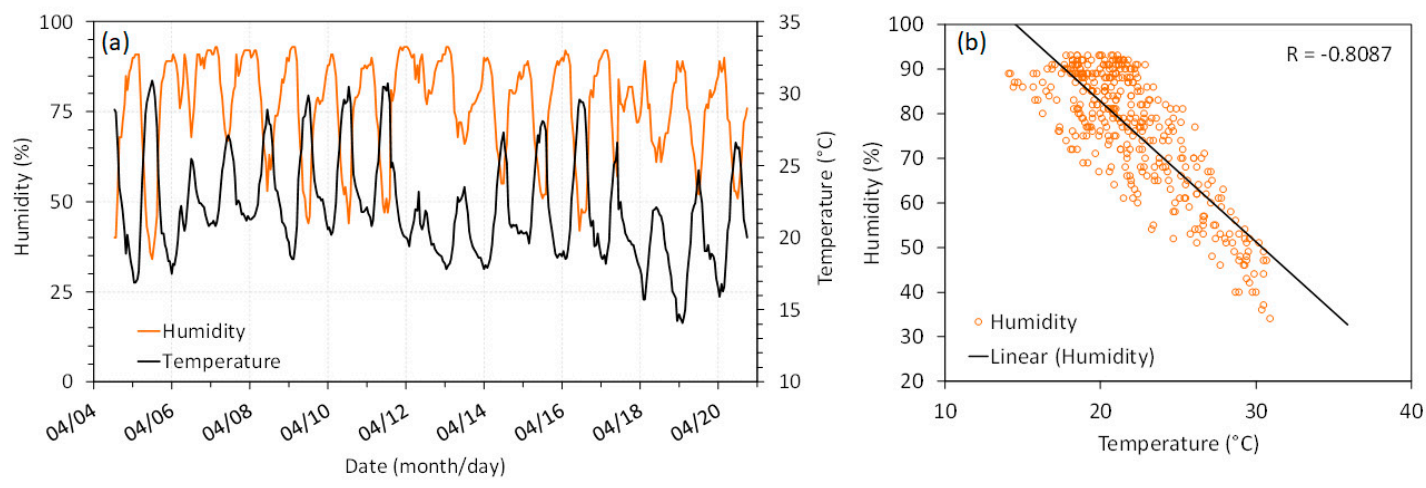

Figure 19. Correlation of temperature and humidity. (a) temporal evolution of both meteorological parameters, (b) Pearson correlation parameter.

A summary of the performed correlation analysis is shown in Table 1 . The values in blue, orange and in red are the moderate, weak and negligible correlations, respectively. We note that both sensors present negative and moderate correlation due to the wind action, except the sensor 2 in the $4^{\text {th }}$ and $5^{\text {th }}$ data sets that corresponds to the change made in sensor 2 to reduce the wind action, showing that the small change made was effective for this end. Regarding temperature, except for the first set of data, sensor 1 presents negative and moderate correlation with temperature. It is believed that this influence comes from the gas equation, as explained above. Basically, an increase in the local temperature decreases the number of molecules inside the compact cell by expanding the gas, reducing 
the concentration. Sensor 2 has no correlation with temperature, probably because it is more exposed to wind cooling. All these hypotheses would be better tested if we had temperature and wind speed sensors in the exact position of each sensor. In terms of mean values, considering the influence of the wind velocity, sensor 1 shown a mean negative moderate correlation coefficient of -0.61 , while sensor 2 had the same mean value for the period from April $4^{\text {th }}$ to June $1^{\text {st }}$ but a drop to -0.30 after this period. Value of correlation considered to be weak to negligible. Regarding the temperature influence sensor 1 presented a mean correlation value of -0.57 (moderate negative correlation) and sensor 2 a mean correlation value of zero, that is a negligible correlation.

Table 1. Summary of correlation analysis.

\begin{tabular}{cccccc}
\hline \multirow{2}{*}{ Period } & \multicolumn{4}{c}{ Correlation } \\
\cline { 2 - 5 } & \multicolumn{2}{c}{ Wind } & \multicolumn{2}{c}{ Temperature } & Humidity and \\
& \multicolumn{1}{c}{ Sensor 1 } & Sensor 2 & Sensor 1 & Sensor 2 & Temperature \\
\hline $1^{\text {st }}$ data set-April 4 to 20 & -0.65 & -0.70 & -0.29 & 0.03 & -0.81 \\
$2^{\text {nd }}$ data set-April 24 to May 11 & -0.56 & -0.58 & -0.66 & -0.28 & -0.91 \\
$3^{\text {rd }}$ data set-May 15 to June 1 & -0.60 & -0.55 & -0.62 & 0.06 & -0.87 \\
$4^{\text {th }}$ data set-June 6 to June 24 & -0.63 & $-0.29^{1}$ & -0.64 & -0.01 & -0.83 \\
$5^{\text {th }}$ data set-June 27 to July 17 & -0.61 & $-0.32^{1}$ & -0.63 & 0.10 & -0.92 \\
\hline
\end{tabular}

${ }^{1}$ Modification on sensor 2 to reduce wind action.

\section{Rainfall Influence}

Based on local meteorological data, it was also possible to observe the influence of rainfall on methane concentration measurements by field sensors. For this, the period of greatest precipitation was analyzed. The highest rainfall incidence occurred, according to data from the weather station, on May 21, 2017 at 10:00 p.m., as can be seen in the graph of Figure 20. By making an expansion of this period we noticed little influence of precipitation on the recorded methane concentration values, as we can see in Figure 20. However, it can be noted that in period 1, indicated in Figure 20, (May 19, from 2 a.m. to 6 p.m.) there is a drop of the methane concentration during the rainfall for both sensors. This drop occurs less sharply on day 21 at about 10:00 p.m. But in general, the system resisted the rainfall effect.

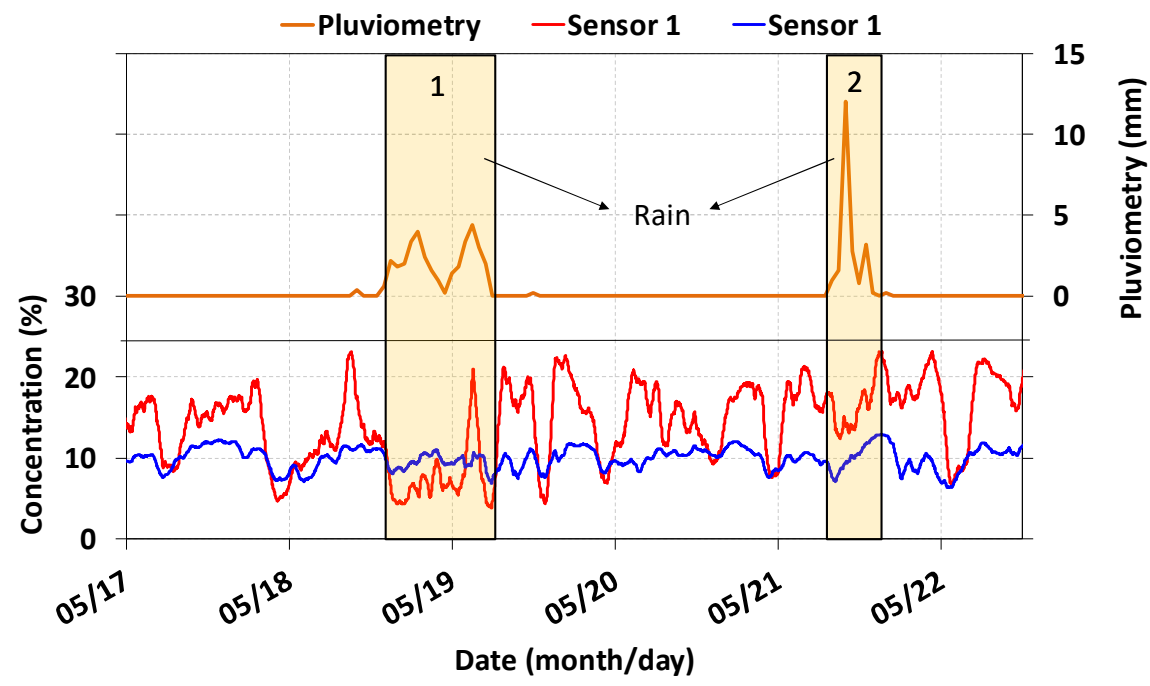

Figure 20. Comparison between the measured concentration by the sensors and the rainfall pluviometry expressed in $\mathrm{mm}$.

In one day of periodical technical inspection of the installed system, the team witnessed the presence of rain on the sensor elements and no alteration was observed in them, even in sensor 2 which 
has a larger opening and a smaller protective "roof", as we can see in Figure 21. In other words, all sensors were dry and operational.

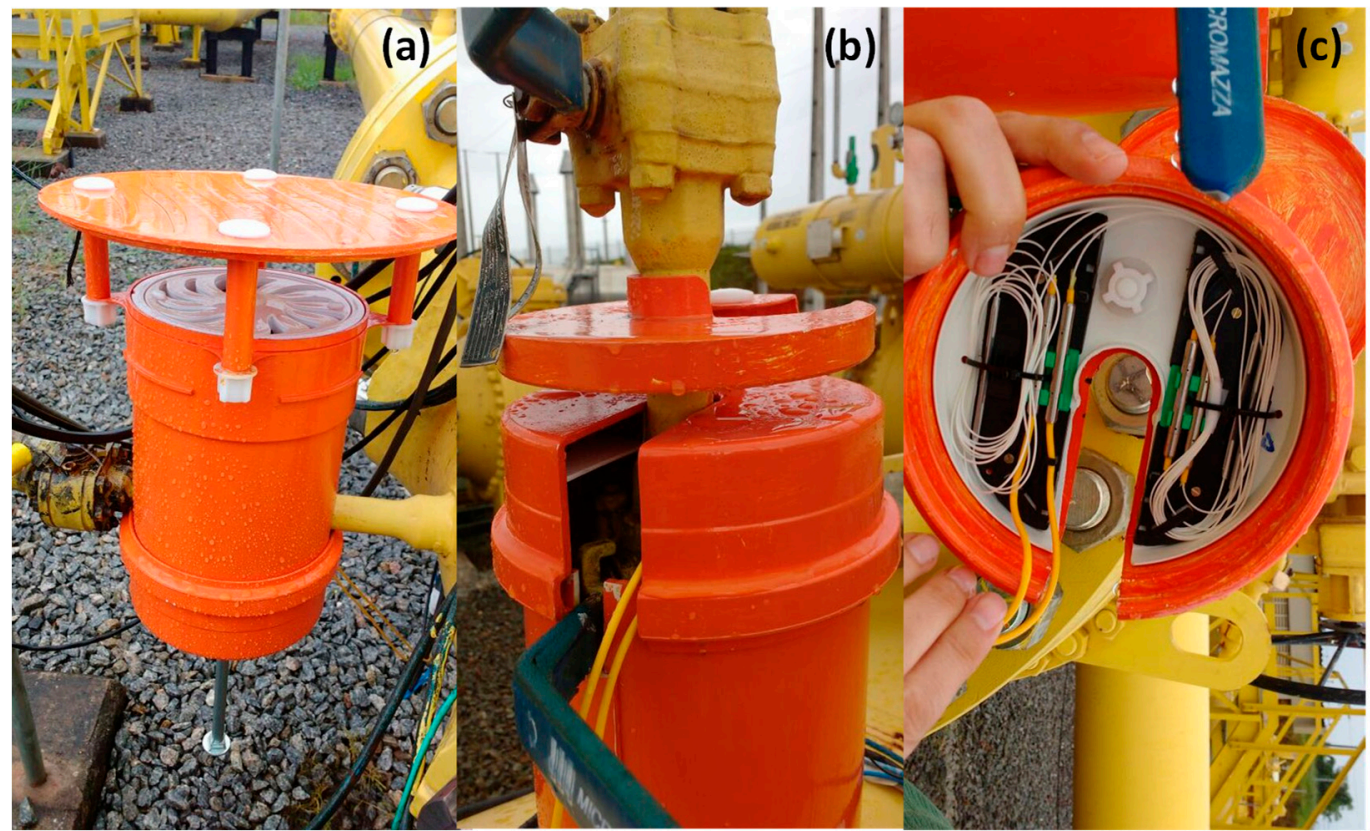

Figure 21. Vision of the sensors in presence of rain: (a) sensor 1, (b) sensor 2, (c) sensor 2 open for verification.

Finally, we note that, although a long term and durability analysis of the system could not be delivered in this field demonstration due to the limited time of operation available for the field test, we can say that system proved to be robust. First, because the interrogation unit is made of standard telecom devices (lasers, semiconductor optical amplifiers (SOA) and optical time domain reflectometer (OTDR) modules) that are widespread and consolidated in telecom systems where high standards are required for its use. Secondly, even though the passive sensors and their collimation cells would represent the most fragile part of the system, the packaging and present data show no degradation in performance during the time the system operated in the field. The dust and residues that would be introduced to the collimation cell would be the more aggressive issue. However, three points are favorable to the proposed system:

(1) The system uses a reference trace acquisition in order to avoid the influence of the attenuation introduced in the system.

(2) The packaging can be improved to avoid such deterioration introducing a protective layer or a labyrinth-like structure that let the gas in at the same time that it avoids the water drops and dust, for example.

(3) A quick replacement of the sensor head would be possible in the severe case when the sensor stopped working.

\section{Conclusions}

In this paper we presented an evaluation of the environmental influences on a novel semi-distributed optical fiber methane leak monitoring system that was developed using passive optical sensors to attend to natural gas production and the transportation industry. The system is based oin optical time domain reflectometry and direct optical absorption spectroscopy. The passive sensors were designed in order to: (i) be easy to install, (ii) mitigate the action of the wind, (iii) let methane free to disperse in the atmosphere and (iv) be adaptable to a number of leak points (valves, vents, flanges, connectors, pumps, etc.). Field tests were carried out in a gas compressor station at Taubaté 
in the state of São Paulo in Brazil over four months. The system was capable to measure methane concentration at two points showing its correlation with meteorological data, especially wind velocity and local temperature. Recorded methane concentrations in this period varied from $2.5 \%$ to $15 \%$ in the first monitored point by sensor 1 , and from $5 \%$ to $30 \%$, in the second point with sensor 2 . Both sensors exhibited a moderate negative correlation with wind velocity with mean Pearson coefficient of -0.61 , despite the external cap designed to avoid the influence of wind. Sensor 2 had a modification in its external package introduced to further reduce the influence of wind. After this modification, the mean correlation coefficient dropped to -0.30 , considered to be weak to negligible. Regarding temperature, a moderate mean correlation of -0.59 was verified for sensor 1 and zero mean correlation was found for sensor 2. The rainfall showed little influence in the measurements, even if a drop could be seen in the measured values. Based on these results the system was proven to be robust for installation in gas transportation or processing facilities; however, the influence of local meteorological phenomena still plays a significant role in the measured values, even with the localized sensor's external protective package designed to mitigate the action of the wind while allowing methane to disperse freely in the atmosphere.

Supplementary Materials: The following are available online at http://www.mdpi.com/2072-4292/11/10/1249/s1, Video V1: The procedure of installation of sensor 1 . The following are available online at http://www.mdpi.com/ 2072-4292/11/10/1249/s2, Video V2: The screen of the system with OTDR traces of reference and measurement as well as the concentrations measured by sensors 1 and 2 .

Author Contributions: Conceptualization, C.F. and J.B.R.; resources, L.M.P.; investigation, C.F., J.B.R., J.P.V.F., F.R.B. and R.S.P.; software, J.P.V.F.; project administration, L.M.P. and M.A.C.d.M.R.; writing-original draft preparation, C.F.

Funding: This research was funded by Petróleo Brasileiro S.A. - Petrobras, grant number PT-136.01.12512 and the APC was partially funded by grant number PT-151.01.12842.

Acknowledgments: CNPq sponsors C. Floridia and J. B. Rosolem under scholarship DT.

Conflicts of Interest: The authors declare no conflict of interest.

\section{References}

1. Yamate, T. Fiber-optic sensors for the exploration of oil and gas. In Proceedings of the 2009 IEEE 14th OptoElectronics and Communications Conference, Hong Kong, China, 13-17 July 2009; pp. 1-2.

2. Anifowose, B.; Odubela, M. Methane emissions from oil and gas transport facilities-Exploring innovative ways to mitigate environmental consequences. J. Clean. Prod. 2015, 92, 121-133. [CrossRef]

3. Jin, W.; Ho, H.L.; Cao, Y.C.; Ju, J.; Qi, L.F. Gas detection with micro- and nano-engineered optical fibers. Opt. Fiber Technol. 2013, 19, 741-759. [CrossRef]

4. Culshaw, B. Optical Fibre Gas Detections Systems; Udd, E., Pickrell, G., Du, H.H., Eds.; SPIE: Baltimore, MD, USA, 2016; p. 98520Y.

5. Esposito, F.; Zotti, A.; Palumbo, G.; Zuppolini, S.; Consales, M.; Cutolo, A.; Borriello, A.; Campopiano, S.; Zarrelli, M.; Iadicicco, A. Liquefied Petroleum Gas Monitoring System Based on Polystyrene Coated Long Period Grating. Sensors 2018, 18, 1435. [CrossRef] [PubMed]

6. Yang, J.; Zhou, L.; Huang, J.; Tao, C.; Li, X.; Chen, W. Sensitivity enhancing of transition mode long-period fiber grating as methane sensor using high refractive index polycarbonate/cryptophane A overlay deposition. Sens. Actuators B Chem. 2015, 207, 477-480. [CrossRef]

7. Culshaw, B.; Kersey, A. Fiber-Optic Sensing: A Historical Perspective. J. Light. Technol. 2008, 26, 1064-1078. [CrossRef]

8. Ho, H.L.; Jin, W.; Demokan, M.S. Sensitive, multipoint gas detection using TDM and wavelength modulation spectroscopy. Electron. Lett. 2000, 36, 1191. [CrossRef]

9. Mcfadden, J. Fiber-Based Methane Leak Detection. In Proceedings of the Offshore Technology Conference, Houston, TX, USA, 6-9 May 2013. 
10. Floridia, C.; Salgado, F.C.; Rosolem, J.B.; Bassan, F.R.; Fracarolli, J.P.V.; Penze, R.S.; Pereira, L.M. Methane leak detection and spectral analysis by using only optical time domain reflectrometry in semidistributed remote optical sensors. In Proceedings of the 2016 IEEE SENSORS, Orlando, FL, USA, 30 October-3 November 2016; pp. 1-3.

11. Pereira, L.M.; Floridia, C.; Rosolem, J.B.; Bassan, F.R.; Fracarolli, J.P.V.; Penze, R.S. Laboratory and Field Test of a Novel Fiber Optic Methane Leak Detection System. Presented at the 110th Annual Conference \& Exhibition of the Air \& Waste Management Association, Pittsburgh, PA, USA, 5-8 June 2017; p. Paper \#260134.

12. Floridia, C.; Rosolem, J.B.; Fracarolli, J.P.V.; Bassan, F.R.; Penze, R.S.; Pereira, L.M. A Remote Fiber Optic Methane Leak Detection System Based in Optical Time Domain Reflectrometry. In Proceedings of the Rio Pipeline Conference \& Exhibition 2017, Rio de Janeiro, Brazil, 24-26 October 2017; p. IBP2143_17.

13. Rothman, L.S.; Gordon, I.E.; Babikov, Y.; Barbe, A.; Chris Benner, D.; Bernath, P.F.; Birk, M.; Bizzocchi, L.; Boudon, V.; Brown, L.R.; et al. The HITRAN2012 molecular spectroscopic database. J. Quant. Spectrosc. Radiat. Transf. 2013, 130, 4-50. [CrossRef]

14. Svanberg, S. Atomic and Molecular Spectroscopy; Advanced Texts in Physics; Springer Berlin Heidelberg: Berlin/Heidelberg, Germany, 2004; ISBN 978-3-540-20382-7.

15. Kirchgessner, D.A.; Lott, R.A.; Michael Cowgill, R.; Harrison, M.R.; Shires, T.M. Estimate of methane emissions from the U.S. natural gas industry. Chemosphere 1997, 35, 1365-1390. [CrossRef]

16. Brazilian National Institute of Meteorology. Taubate Automated Surface Weather Station. Available online: http://www.inmet.gov.br/sonabra/pg_dspDadosCodigo_sim.php?QTcyOA (accessed on 10 August 2017).

17. Hinkle, D.E.; Wiersma, W.; Jurs, S.G. Applied Statistics for the Behavioral Sciences; Houghton Mifflin: Boston, MA, USA, 2003; ISBN 978-0-618-12405-3.

18. Zou, K.H.; Tuncali, K.; Silverman, S.G. Correlation and Simple Linear Regression. Radiology 2003, 227, 617-628. [CrossRef] [PubMed]

19. Pearson Correlation Coefficient. Available online: https://en.wikipedia.org/wiki/Pearson_correlation_ coefficient (accessed on 8 October 2017).

(C) 2019 by the authors. Licensee MDPI, Basel, Switzerland. This article is an open access article distributed under the terms and conditions of the Creative Commons Attribution (CC BY) license (http://creativecommons.org/licenses/by/4.0/). 